\title{
IMMEDIATE REHABILITATION OF ATROPHIED MANDIBLE WITH “ALL ON FOUR" IMPLANT SUPPORTED FIXED PROSTHESIS WITH AND WITHOUT CANTILEVER EXTENSIONS. ONE YEAR CLINICAL AND RADIOGRAPHIC STUDY
}

\author{
Sherif Aly Sadek *, Hisham Mohamed Abbas ${ }^{* *}$ and Hazem Shawky Shoshan ${ }^{* * *}$
}

\begin{abstract}
Aim: The purpose of this study was to evaluate clinical and radiographic results of implant supported fixed prosthesis with and without cantilever extensions for "All on four" implant rehabilitation of atrophied mandible.

Materials and methods: Ten completely edentulous individuals with atrophied mandibular ridges were classified into 2 groups: 1) Group I: included 5 patients with posteriorly placed mental foramen, 2) Group II: included 5 patients with anteriorly placed mental foramen. All participants were managed by 4 implants according to the "All on four" protocol using a Nobel Biocare metal guide and open flap surgery. Implants were immediately loaded by existing mandibular dentures. Group I restored with fixed prosthesis without cantilevers, and group II restored with fixed prosthesis with distal short cantilevers. Plaque and gingival index, probing depth, implant mobility and bone loss (using cone beam CT) were evaluated after prosthesis delivery (T0), six months (T6) and 12 months (T12) after delivery
\end{abstract}

Results: For posterior implants, group II showed significant higher plaque index, and gingival index than group I after 6 and 12 months. No differences in probing depth, implant mobility and bone resorption between groups was noted for anterior and posterior implants. Posterior implant showed significant higher plaque scores (for both groups) and gingival scores (for group II) than anterior implants after 6 and 12 months. Posterior implant showed significant higher pocket depth for both groups.

Conclusion: Within the limitation of this study, fixed prosthesis with short cantilever can be used successfully to rehabilitate patients with atrophied mandibular ridges and anteriorly placed mental foramen with "All on four" concept as it was associated with favourable clinical and radiographic outcomes similar to prosthesis without cantilevers

KEYWORDS: All On Four, cantilever extension implant rehabilitation, Implant supported prosthesis.

\footnotetext{
* Lecturer, Department of Prosthodontics, Faculty of Oral and Dental Medicine, Cairo University, Egypt.

** Lecturer, Department of Oral and Maxillofacial Radiology, Faculty of Oral and Dental Medicine, Cairo University, Egypt.

*** Lecturer, Department of Oral and Maxillofacial Surgery, Faculty of Oral and Dental Medicine, Cairo University, Egypt.
} 


\section{INTRODUCTION}

The rehabilitation of edentulous patient with conventional denture for many years often lead to severe mandibular alveolar bone atrophy, with superficialization of the alveolar nerve. The patients usually have high muscle attachments, sensitive mucosa, knife-edged ridges, sharp mylohyoid projections, and superficial mental nerve ${ }^{1}$. This increase pain and discomfort during mastication and may limit placement of implants in a conventional manner. In such cases, the surgical approach for implant rehabilitation should take into account the patient's anatomical condition especially the posterior ridge $^{2}$. The implant prosthetic options for mandibular atrophy include implant supported overdentures, or implant-supported fixed prostheses. However, implant overdentures are mucosal supported and the patients usually desire a fixed prosthesis that is totally supported by implants. Bone augmentation is needed to achieve sufficient bone support in the posterior severely atrophic mandible. However, this procedure has higher risk of patient morbidity and complications (e.g., infection, loss of graft material) as well as higher costs and longer time intervals to complete the treatment ${ }^{3}$. Another option is repositioning of inferior alveolar nerve by lateralization or transposition. however, this technique usually associated with neurosensory disturbance ${ }^{4}$

With All-on-Four treatment, bone augmentation and inferior alveolar nerve displacement are omitted. The concept involve strategic implant positioning to enhance prosthetic support (i.e., two implants inserted vertically in the canine regions and two distally tilted implants $\left(30^{\circ}\right)$ just mesial to the mental foramen $)^{5,6}$. This approach provides long posterior implants, improves the bone/implant anchorage. Furthermore, restoration support is improved due to increasing the anteroposterior spread and shortening of cantilevers which provide optimum load sharing. Additionally, the grafting procedures may be omitted, causing reduced morbidity and costs. Moreover, the immediate function concept represents a major advantage for patients, providing less time-consuming treatments ${ }^{7,8}$. Most definitive prostheses included 12 teeth thanks to good locations obtained by distal tilting of the posterior fixtures. ${ }^{9}$

The conventional location of mental foramen is in the second premolar area or between the premolars (posterior mental foramen). In some anatomical conditions, advanced mandibular atrophy may be associated with anterior positioning of mental foramen (anterior mental foramen) or medially extended loop of mental nerve. ${ }^{11,12}$

In these situations, distal tilting of the implants may not reach $30^{\circ}$, and may not provide a wider prosthetic support due to shortening of anteroposterior spread. To solve this problem; angling the implant transalveolarly from buccal toward lingual without the use of cantilevers may be used ${ }^{10}$. However, this carries high risk of lingual plate perforation especially with presence of lingual concavities. Another option is to use a $10 \mathrm{~mm}$ cantilever distal to the posterior implants ${ }^{11}$.

Adding a cantilever to the final All on Four implant prosthesis still a matter of controversy. Zyl et al. ${ }^{12}$ in a study of mandibular cantilever superstructure concluded that extension of cantilever beyond $15 \mathrm{~mm}$ resulted in increased stress in the lingual and buccal sides of the implants, which may compromise the osseointegration of the implant. Horita et al. ${ }^{13}$ found that cantilever length was directly proportional to the increase in periimplant stresses. The stress in the $15-\mathrm{mm}$ cantilever models caused a 33\% increase in stresses compared with the 5-mm cantilever. In contrast, Malhotra et al. ${ }^{14}$, in a finite element analysis did not found any significant difference in stress and strains between $4 \mathrm{~mm}$ and $12 \mathrm{~mm}$ cantilever lengths for both $30^{\circ}$ and $40^{\circ}$ posteriorly tilted implants for all on four prothesis. However, the clinical and radiographic evaluation of the cantilevered All on four fixed prosthesis was not a concern. Accordingly, the aim 
of the present study was to evaluate the clinical and radiographic outcomes of implant supported fixed prosthesis with and without cantilever extensions for "All on four" implant rehabilitation of atrophied mandible. The null hypothesis was that there will be no significant difference in outcomes between prostheses with and without cantilever extensions.

\section{MATERIAL AND METHODS}

Ten completely edentulous individuals with mean age of $59 \pm 5.3$ years were included in this study from outpatient clinic of Prosthodontic Department of Alfarabi Private College for Dentistry and Nursing-Jeddah, Kingdom of Saudi Arabia.

The included participants had the following criteria: 1) atrophied mandibular ridges (class IVVI) according to the classification proposed by (Cawood \& Howell ${ }^{15}$ ) with insufficient retention and patient complain from instability of mandibular dentures, 2) sufficient bone height and width in the interforaminal area to receive four implants with standard diameter (at least $11 \mathrm{~mm}$ long and 3.7 $\mathrm{mm}$ wide). The exclusion criteria were: 1) serious problems of coagulation,2) diseases of the immune system, 3) uncontrolled diabetes, 4) metabolic diseases affecting bone, 5) irradiation of the head or neck region in the last 2 years, and 6) inadequate oral hygiene level. The patients instructed about the treatment protocol and objectives prior to obtain an informed consent. The study was conducted according the ethical principles of Helsinki Declaration (https://www.wma.net/). The participants were classified into 2 groups according to location of the mental foramen: 1) Group I: included 5 patients with posteriorly placed mental foramen who received 4 implants according to the All on Four concept and restored with fixed prosthesis without cantilevers, 2) Group II: included 5 patients with anteriorly placed mental foramen who received 4 implants according to the All on Four concept and restored with fixed prosthesis with distal cantilevers. Allocation of the patients to treatment groups was made using a quasi-random method by random generated numbers generated in Excel sheet. The randomization was done in a manner that ensure equal gender distribution in both groups. The demographic data of both groups are presented in table 1 .

TABLE (1) Demographic distribution of patients in both groups

\begin{tabular}{|l|c|c|}
\hline \multicolumn{2}{|c|}{ Group I(n=5) } & Group II(n=5) \\
\hline Mean age (years) & 58 & 60 \\
\hline $\begin{array}{l}\text { Gender } \\
\text { (male/female) }\end{array}$ & $3 / 2$ & $3 / 2$ \\
\hline $\begin{array}{l}\text { Causes of teeth } \\
\text { extraction }\end{array}$ & $\begin{array}{c}\text { Periodontal, } \mathrm{n}=2 \\
\text { Pupal, } \mathrm{n}=3\end{array}$ & $\begin{array}{l}\text { Periodontal, } \mathrm{n}=3 \\
\text { Pulpal, } \mathrm{n}=2\end{array}$ \\
\hline $\begin{array}{l}\text { Duration of } \\
\text { edentulous state } \\
\text { (years) }\end{array}$ & 8 & 12 \\
\hline $\begin{array}{l}\text { Complains from } \\
\text { previous dentures }\end{array}$ & $\begin{array}{c}\text { Instability, } \mathrm{n}=2 \\
\text { Pain, } \mathrm{n}=1\end{array}$ & $\begin{array}{l}\text { Instability, } \mathrm{n}=5 \\
\text { Pain, } \mathrm{n}=3\end{array}$ \\
$\begin{array}{l}\text { Inability to chew, } \\
\mathrm{n}=2\end{array}$ & $\begin{array}{l}\text { Inability to chew, } \\
\mathrm{n}=4\end{array}$ \\
\hline
\end{tabular}

\section{Surgical and prosthetic procedures}

All patients received new maxillary and mandibular conventional dentures. The new mandibular denture was duplicated into acrylic resin radiographic template (with gutta-perchae radiopaque markers fitted to the fitting and polished surface). Patients underwent CT scans (CBCT, i- CAT Vision ${ }^{\circledR}$, Imaging Sciences International, Hatfield, PA, USA) to accurately assess the quantity of bone and location of mental foramen, mental loop and mandibular canal. All patients were sedated with diazepam prior to surgery. Antibiotics (amoxicillin $625 \mathrm{mg}+$ clavulanic acid $125 \mathrm{mg}$, Augmentin ${ }^{\circledR} 1 \mathrm{gm}$ ) were given 1 hour prior to surgery and daily for 6 days thereafter. Cortisone medication (Dexamethazone ${ }^{\circledR}$ ) was given. 
Anti-inflammatory medication (ibuprofen $\AA$, $600 \mathrm{mg}$ ) was administered for 4 days postoperatively. Analgesics (Ketolac ${ }^{\circledR} 10 \mathrm{mg}$ ) were given on the day of surgery and postoperatively for the first 4 days. Local anesthesia was administered. A mid crestal incision was made and a mucoperiosteal flap was raised to expose the crest and the mental foramina. When needed bone flattening was made to provide a flat shelf that used to establish optimal implant position and angulation to maximize implant fixation for immediate loading ${ }^{10}$.

Each patient received 4 implants (TioLogic, Dentaurum) according to the "All-on-4 concept" (Malo, et al. 2003a) using a special metal guide (Malo edentulous guide ${ }^{\mathrm{TM}}$, Nobel Biocare AB). (figure 1).

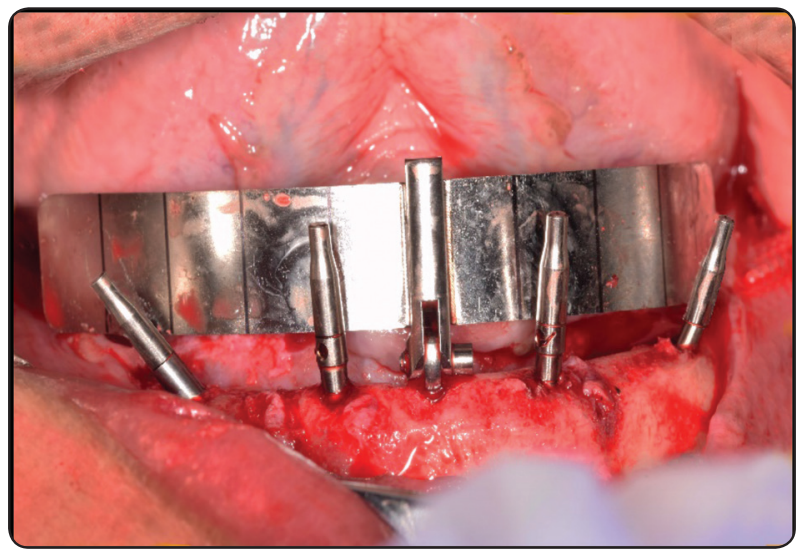

Fig. (1): Osteotomy preparation, guiding pins using Nobel Biocare metal guide.

Anterior implants were inserted at canine/ lateral incisor area parallel to each other and perpendicular to occlusal plane. Posterior implants were inserted in premolar area just anterior to mental foramina and tilted $30-35^{\circ}$ distally to emerge in the region of mesial cusp of the first molar tooth (Group I) (figure 2 a). This placement enhances good implant anchorage and support, shortens cantilever length, and increases anteroposterior spread (Krekmanov, et al. 2000). In group II, most posterior implants were placed close to the anterior wall of the mental loop and were tilted distally about $30^{\circ}$ relative to the occlusal plane (figure 3 a). The implant emerged at the second bicuspid location and first molar teeth were cantilevered. The implants were inserted with a minimum torque of $40 \mathrm{Ncm}$ to allow immediate loading. Reduction of the width of osteotomy preparation was made with reduced bone density to obtain high primary implant stability ${ }^{11}$. Straight multiunit abutments (AngleFix abutments, TioLogic, Dentaurum) were screwed in the canine implants and 30-degree multiunit abutment were screwed into posterior implants. All abutments were torqued at $25 \mathrm{Ncm}$.
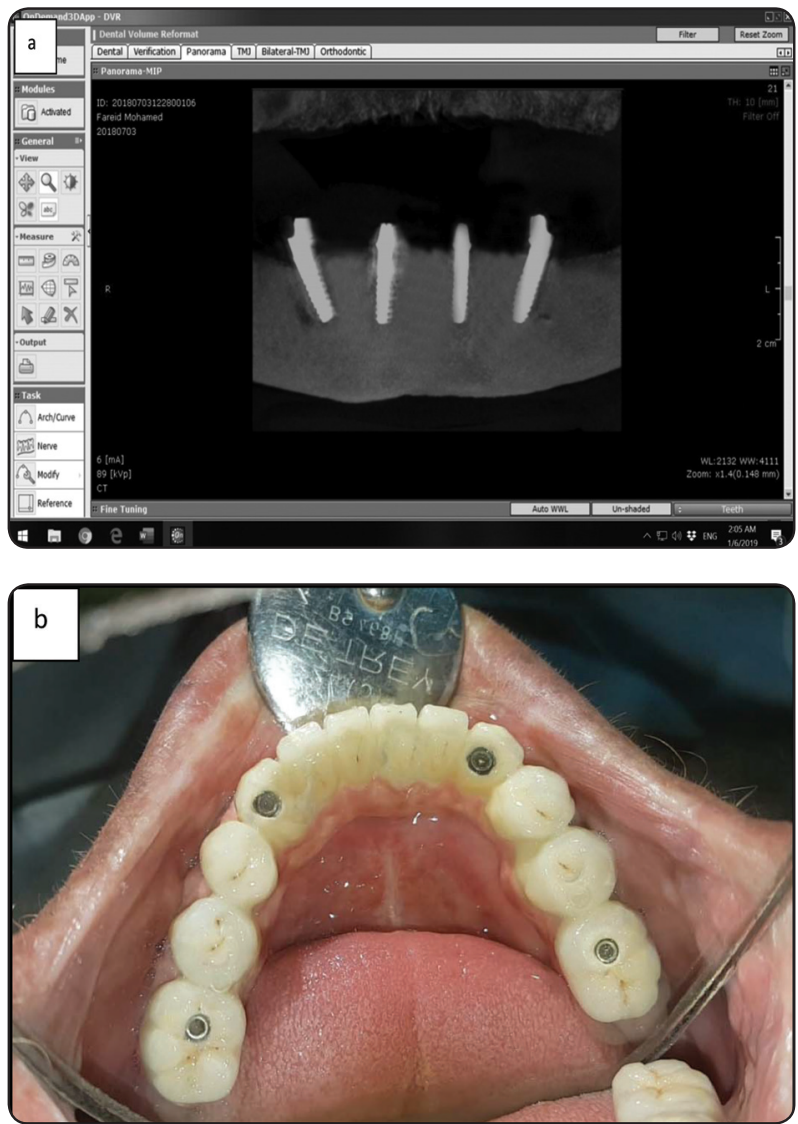

Fig. (2): Group I. Posteriorly placed mental foramen with 4 implants installed according to the All on Four concept and restored with fixed prosthesis without cantilevers. (a- Radiographically. b- Intra-orally). 

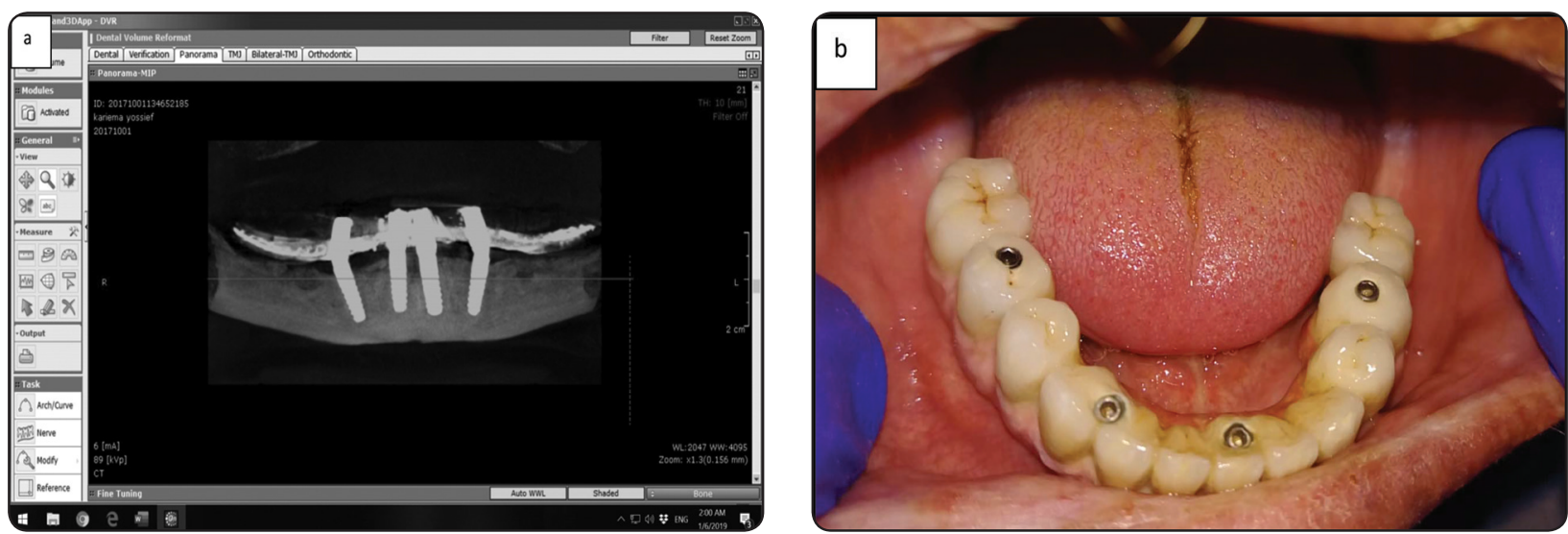

Fig. (3): Group II. Anteriorly placed mental foramen with 4 implants installed according to the All on Four concept and restored with fixed prosthesis with one tooth (first molar) cantilevers. (a- Radiographically. b- Intra-orally).

Implants were immediately loaded by existing mandibular dentures. The denture base was hollowed and the mandibular denture was modified by removal of denture flanges and second molar artificial teeth. Temporary metal caps were screwed to the multiunit abutments and picked up to the modified denture using auto polymerized acrylic resin ${ }^{2}$. The occlusal contact on provisional mandibular denture was limited to canine and incisors in centric occlusion; and posterior occlusal contacts were eliminated to avoid lateral force on the inclined implants. Anterior occlusal contacts and canine guidance during lateral movements were made in the provisional prosthesis ${ }^{16}$. Participants were instructed for oral hygiene procedures and informed to attend regular follow-up visits. Patients were advised to adhere to a soft diet for the first 2 months post-surgery and to return to a regular diet, but avoid harder food items for another 2 months.

After 3 months integration period, an abutment level open tray impression procedure was made using a polyvinilsyloxane (Zhermack ${ }^{\circledR}$, Badia Polesine, Rovigo, Italy). To minimize movement of the transfer coping during impression making, the copings were splinted with ligature wire and Duralay autopolymerized resin pattern (Duralay, Reliance Dental MFG Co, Worth, IL, USA) on the casts (figure 4). The splinting resin bars between the implants were sectioned and assembled intraorally to obtain passive fit before making the impressions. On the cast, the plastic caps were connected to multiunit abutments. The cast was scanned using a CAD/CAM device (Ceramill Map400, Amann Girrbach AG. Koblach, Austria), then a cast metalceramic fixed prostheses that replace lost gingival tissues with pink porcelain was planned using the software of the device. The fixed partial denture was milled in polymerized resin disc and tried in patient mouth for passive fit. The resin pattern was cast in a nonprecious cobalt-chromium alloy (Heraenium Pw, Heraeus-Kulzer GmbH, Hanau, Germany). The cast superstructure was tried intraorally for passivity using the single screw Sheffield test. The porcelain powder (Heraeus-Kulzer GmbH, Hanau, Germany) was mixed with the modeling liquid, applied onto the cobalt- chromium metal substructure over the opaque layer, fired, finished and glazed. The fixed partial denture has 12-unit artificial teeth in both groups with no cantilevers in group I (figure $2 \boldsymbol{b}$ ) and maximum $12 \mathrm{~mm}$ cantilever in group II (figure $3 \boldsymbol{b}$ ) (which represent the width of first molar tooth). In this final prosthesis, the occlusion mimicked natural dentition ${ }^{17}$. The final prosthesis was delivered typically 3 months post-surgically. The screws access holes were sealed with composite resin ${ }^{11}$ 


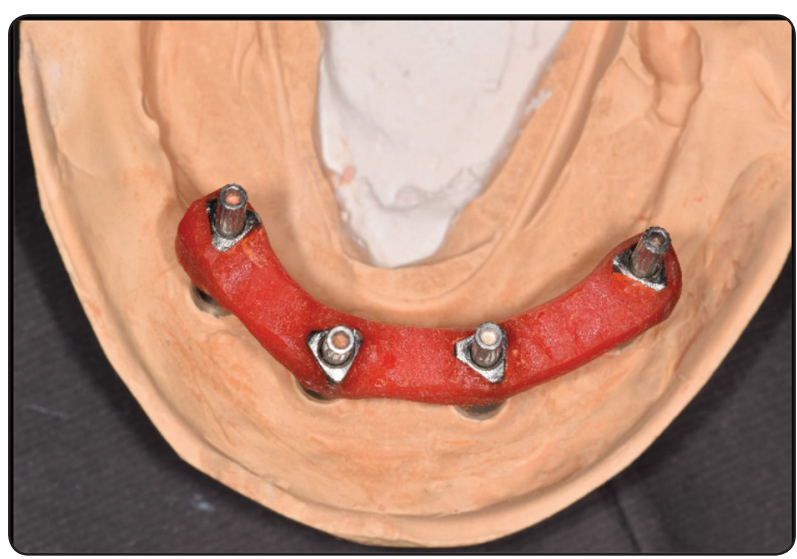

Fig. (4): Splinting of the transfer coping on the cast.

\section{Clinical and radiographic evaluations}

Clinical and radiographic evaluations of periimplant tissues were performed after prosthesis delivery (T0), six months (T6) and 12 months (T12) after delivery. Plaque index and gingival index were evaluated using the Mombelli indices 18. A graduated plastic probe was used to measure the pocket depth in $\mathrm{mm}^{19,20}$. Implant mobility was assessed using resonance frequency analysis. The Osstell device (Integration Diagnostics Ltd.) expresses the mobility as implant stability quotient. The multiunit abutments were removed and smart pigs of the Ostell device were connected to the internal hex of the implants. Plaque index, gingival index and probing depth were measured at the midfacial, mid-lingual, mid-mesial, and mid-distal aspects of each fixture.

Peri-implant bone loss was measured using cone beam computed tomography (CBCT, i-CAT ${ }^{\circledR}$ apparatus. Hatfield, PA, USA) according to the procedure described by Elsyad et al. ${ }^{21}$. The acquired and reconstructed three-dimensional images were exported as DICOM-files. Two vertical crosssectional images perpendicular to the long axis of each implant were reconstructed; 1) mesiodistal (MD) image: bisect the ridge and the implants mesiodistally, 2) buccolingual (BL) image: bisect the implant buccolingually (figure 5). This resulted in four sites; mesial, distal, buccal, and lingual. Using the software (OnDemand3DApp Software, Seoul, South Korea), peri-implant marginal vertical bone level, was measures as the distance between implant abutment connection (A point) and bone to implant contact (B point) was used (figure 6). Vertical bone loss was calculated by subtracting bone height values at 6 months and 1 years from values at base line. The mean of measurements of buccal, lingual, mesial and distal sides was used for each fixture. The mean measurements of right and left fixtures were subjected to statistical analysis.

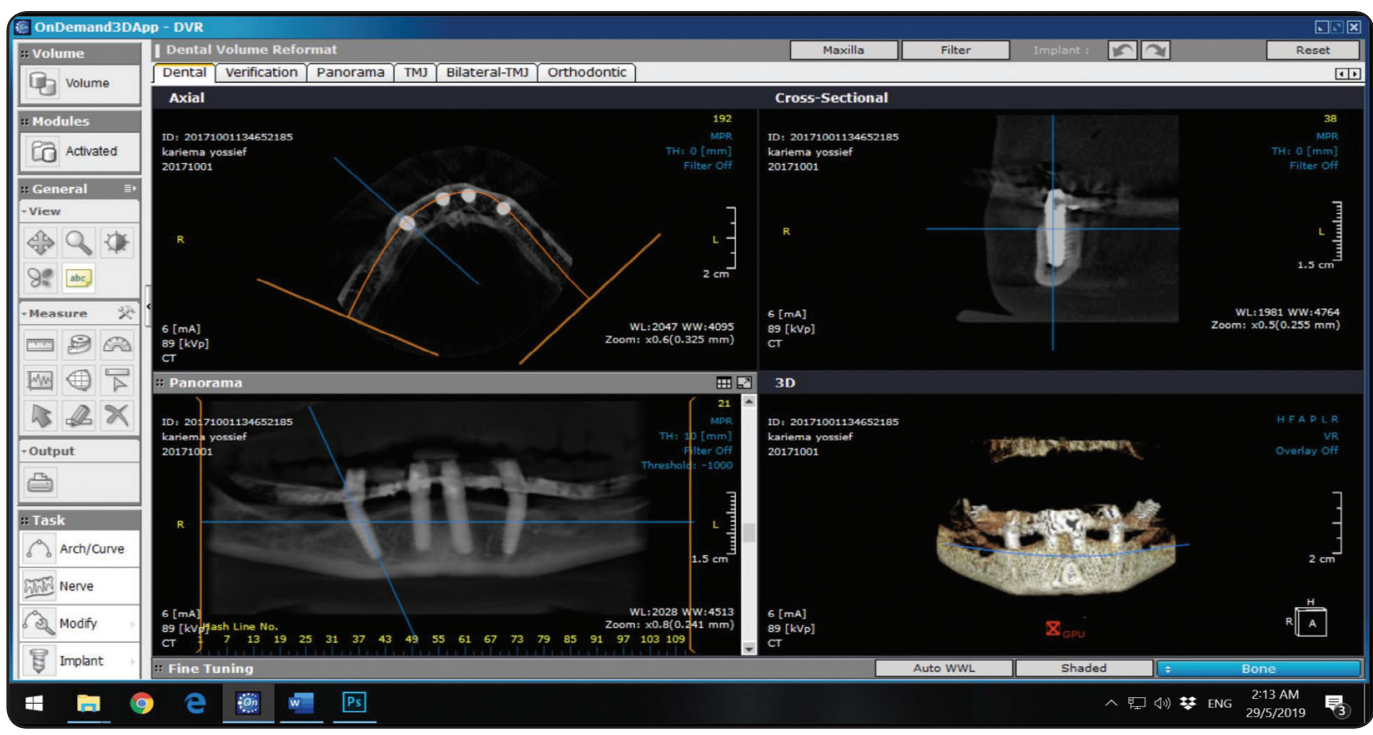

Fig. (5): Cross-sections of CBCT. 


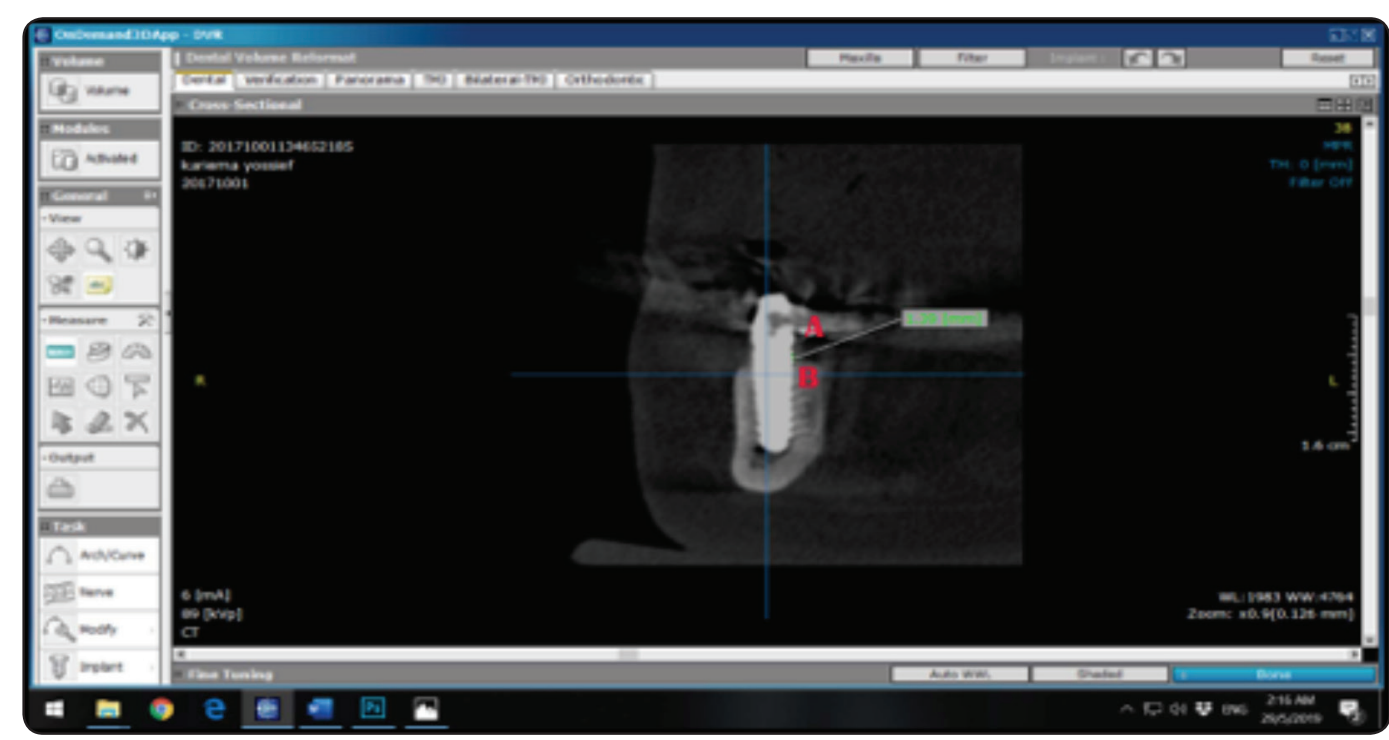

Fig. (6): Marginal bone height measurements.

\section{Statistical analysis}

The data were analyzed using SPSS $\AA$ software version 22 (SPSS Inc., Chicago, IL, USA). Mann Whitney test was used for comparisons between groups. The difference between observation times was detected using Friedman test followed by Wilcoxon signed ranks test for pair-wise comparison between observation times. P-values $<0.05$ were considered to be significant.

\section{RESULTS}

One posterior implant failed to integrate in each group. The failures were due to overload and were associated with mobility and marginal bone loss without suppuration. The implants were excluded from the study resulting in $95 \%$ survival rate in each group after exclusion. The failed implants were removed and additional 2 implants with larger diameter were inserted after irrigation of the implant sockets and the implants were left to integrate submerged without implant loading.

Comparisons of measured outcomes between observation times for anterior and posterior implants are shown in table 2 and table 3 respectively and in fig 7-11. For both groups, anterior and posterior implants showed significant increase of plaque index, pocket depth, and bone resorption with time $(\mathrm{p}<.001)$. No difference in gingival index between observation times was noted for Group I. However, gingival index increased significantly with time in group II for posterior implants. Multiple comparisons of each 2-time intervals are presented in the same tables.

Comparison of outcomes between groups for anterior and posterior implants are presented in table 2 and table 3 respectively. For anterior implants, no significant difference in plaque index, gingival index, pocket depth implant mobility and bone resorption between groups was noted. For posterior implants, group II showed significant higher plaque index, and gingival index than group I after 6 and 12 months. No differences in probing depth, implant mobility and bone resorption between groups was noted for posterior implants.

Comparisons of measured outcomes between anterior and posterior implants for both groups at time intervals are shown in table 4. Posterior implant showed higher plaque scores than anterior implants in both groups after 6 and 12 months. Posterior implant showed higher gingival scores than anterior 
implants for group II only after 6 and 12 months. for both groups after 12 months. No difference in No difference in gingival scores (group I) and bone loss (both groups) between anterior and posterior implants was noted after 6 and 12 months. Posterior implant showed significant higher pocket depth implant mobility between anterior and posterior implants was noted for both groups at different observation times.

TABLE (2): Comparison of measured outcomes between observation times and between groups for anterior implants

\begin{tabular}{|c|c|c|c|c|}
\hline & Base line & 6 months & 12 months & $\begin{array}{l}\text { Freidman test } \\
\text { (p value) }\end{array}$ \\
\hline \multicolumn{4}{|c|}{ Plaque indices } & \\
\hline Group I Med(Mini-Maxi) & $.00(.00-1.00)$ & $.00(.00-.100)$ & $1.00(1.00-2.00)$ & $.003 *$ \\
\hline Group II Med(Mini-Maxi) & $.00(.00-1.00)$ & $.00(.00-2.00)$ & $1.00(1.00-3.00)$ & $.002 *$ \\
\hline MannWhitney Test (p value) & .06 & .09 & .13 & \\
\hline \multicolumn{5}{|c|}{ Gingival indices } \\
\hline Group I Med(Mini-Maxi) & $.00(.00-.00)$ & $.00(.00-.00)$ & $.00(.00-.00)$ & 1.00 \\
\hline Group II Med(Mini-Maxi) & $.00(.00-.00)$ & $.00(.00-.00)$ & $.00(.00-.00)$ & 1.00 \\
\hline MannWhitney Test ( $p$ value) & 1.00 & 1.00 & 1.00 & \\
\hline \multicolumn{5}{|c|}{ Pocket depth } \\
\hline Group I Med(Mini-Maxi) & $.49 \pm .37$ & $1.83 \pm .94$ & $1.91 \pm .86$ & $<.001 *$ \\
\hline Group II Med(Mini-Maxi) & $.62 \pm .40$ & $2.01 \pm 1.05$ & $2.12 \pm .91$ & $<.001 *$ \\
\hline MannWhitney Test (p value) & .15 & .051 & .12 & \\
\hline \multicolumn{5}{|c|}{ Implant mobility } \\
\hline Group I $(X \pm S D)$ & $65.45 \pm 1.77$ & $65.01 \pm 1.68$ & $66.40 \pm 1.59$ & .098 \\
\hline Group II $(X \pm S D)$ & $66.70 \pm 1.61$ & $66.40 \pm 1.62$ & $67.80 \pm 1.01$ & .066 \\
\hline MannWhitney Test (p value) & .30 & .31 & .20 & \\
\hline \multicolumn{5}{|c|}{ Marginal bone resorption } \\
\hline Group I $(X \pm S D)$ & - & $.52 \pm .85$ & $.84 \pm .74$ & $<.001 *$ \\
\hline Group II (X \pm SD) & - & $.69 \pm .78$ & $.97 \pm 1.18$ & $<.001 *$ \\
\hline MannWhitney Test (p value) & - & .75 & .82 & \\
\hline
\end{tabular}

Med= median, mini= minimum; maxi= maximum; $X=$ mean; SD=Standard deviation; different letters in the same raw indicate significant difference between each 2-time intervals. *= significant at .05 level 
TABLE (3): Comparison of clinical and radiographic outcomes between time intervals and between groups for posterior implants

\begin{tabular}{|c|c|c|c|c|}
\hline & Base line & 6 months & 12 months & $\begin{array}{c}\text { Freidman test } \\
\text { (p value) }\end{array}$ \\
\hline \multicolumn{5}{|l|}{ Plaque indices } \\
\hline Group I Med(Mini-Maxi) & $.00(0.00-1.00)$ & $1.00(1.00-.200)$ & $1.00(1.00-3.00)$ & $<.001 *$ \\
\hline Group II Med(Mini-Maxi) & $.00(0.00-1.00)$ & $1.00(2.00-3.00)$ & $2.00(2.00-3.00)$ & $<.001 *$ \\
\hline MannWhitney Test (p value) & 1.00 & $.024 *$ & $.002 *$ & \\
\hline \multicolumn{5}{|l|}{ Gingival indices } \\
\hline Group I Med(Mini-Maxi) & $.00(.00-.00)$ & $.00(.00-.00)$ & $.00(.00-.00)$ & 1.00 \\
\hline Group II Med(Mini-Maxi) & $.00(.00-.00)$ & $1.00(.00-1.00)$ & $1.00(.00-2.00)$ & $.011^{*}$ \\
\hline MannWhitney Test (p value) & 1.00 & $.023^{*}$ & $.037 *$ & \\
\hline \multicolumn{5}{|l|}{ Pocket depth } \\
\hline Group I Med(Mini-Maxi) & $.45 \pm .34$ & $1.82 \pm .47$ & $2.42 \pm .61$ & $<.001 *$ \\
\hline Group II Med(Mini-Maxi) & $.55 \pm .41$ & $2.00 \pm .79$ & $2.50 \pm .48$ & $<.001^{*}$ \\
\hline MannWhitney Test (p value) & .11 & .28 & .81 & \\
\hline \multicolumn{5}{|l|}{ Implant mobility } \\
\hline Group I $(X \pm S D)$ & $66.25 \pm 1.88$ & $67.25 \pm 1.78$ & $67.15 \pm 1.96$ & .12 \\
\hline Group II $(X \pm S D)$ & $67.01 \pm 1.64$ & $67.01 \pm 1.68$ & $68.10 \pm 1.87$ & .35 \\
\hline MannWhitney Test (p value) & .30 & .30 & .45 & \\
\hline \multicolumn{5}{|l|}{ Marginal bone resorption } \\
\hline Group I $(X \pm S D)$ & - & $.68 \pm .43$ & $.98 \pm .75$ & $<.001 *$ \\
\hline Group II $(X \pm S D)$ & - & $.76 \pm .24$ & $1.1 \pm .65$ & $<.001 *$ \\
\hline MannWhitney Test (p value) & - & .45 & .052 & \\
\hline
\end{tabular}

Med= median, mini= minimum; maxi= maximum; $X=$ mean; $S D=$ Standard deviation; different letters in the same raw indicate significant difference between each 2-time intervals. * = significant at .05 level

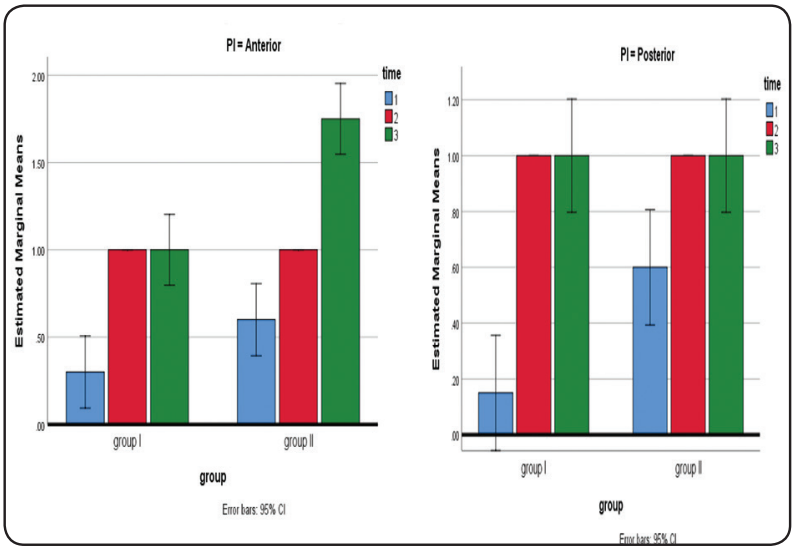

Fig. (7): Plaque scores for anterior and posterior implants at different time intervals for both groups

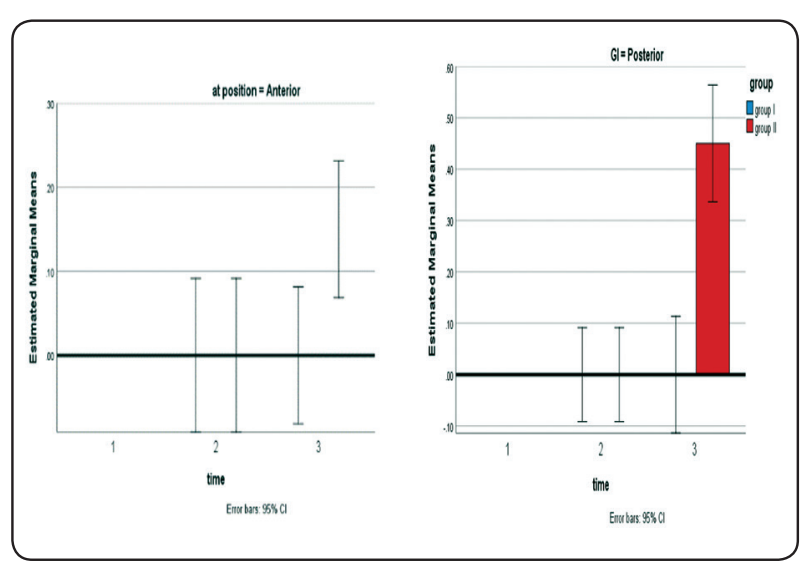

Fig. (8): Gingival scores for anterior and posterior implants at different time intervals for both groups 
TABLE (4): Comparisons of measured outcomes between anterior and posterior implants for both groups at different observation times

\begin{tabular}{|c|c|c|c|c|c|c|}
\hline & \multicolumn{2}{|c|}{ Base line } & \multicolumn{2}{|c|}{6 months } & \multicolumn{2}{|c|}{12 months } \\
\hline & Group I & Group II & Group I & Group II & Group I & Group II \\
\hline \multicolumn{7}{|c|}{ plaque index } \\
\hline Anterior & .00 & .00 & .00 & .00 & 1.00 & 1.00 \\
\hline Med(Mini-Maxi) & $(.00-1.00)$ & $(.00-1.00)$ & $(.00-.100)$ & $(.00-2.00)$ & $(1.00-2.00)$ & $(1.00-3.00)$ \\
\hline Posterior & .00 & .00 & 1.00 & 1.00 & 1.00 & 2.00 \\
\hline Med(Mini-Maxi) & $(0.00-1.00)$ & $(0.00-1.00)$ & $(1.00-.200)$ & $(2.00-3.00)$ & $(1.00-3.00)$ & $(2.00-3.00)$ \\
\hline $\begin{array}{c}\text { Mann Whitney Test } \\
\text { (p value) }\end{array}$ & 1.00 & 1.00 & $.045^{*}$ & $.023 *$ & $.010^{*}$ & $.022 *$ \\
\hline \multicolumn{7}{|c|}{ gingival index } \\
\hline $\begin{array}{c}\text { Anterior } \\
\text { Med(Mini-Maxi) }\end{array}$ & $.00(.00-.00)$ & $.00(.00-.00)$ & $.00(.00-.00)$ & $\begin{array}{c}.00 \\
(.00-.100)\end{array}$ & $\begin{array}{c}.00 \\
(.00-.00)\end{array}$ & $\begin{array}{c}.00(.00- \\
1.00)\end{array}$ \\
\hline $\begin{array}{c}\text { Posterior } \\
\text { Med(Mini-Maxi) }\end{array}$ & $.00(.00-.00)$ & $.00(.00-.00)$ & $.00(.00-.00)$ & $\begin{array}{c}1.00 \\
(.001 .00)\end{array}$ & $\begin{array}{c}.00 \\
(.00-.00)\end{array}$ & $\begin{array}{c}.1 .00(.00- \\
2.00)\end{array}$ \\
\hline $\begin{array}{c}\text { MannWhitney } \\
\text { Test (p value) }\end{array}$ & 1.00 & 1.00 & 1.00 & $.027 *$ & 1.00 & $.030 *$ \\
\hline \multicolumn{7}{|c|}{ pocket depth } \\
\hline $\begin{array}{l}\text { Anterior } \\
\mathbf{X} \pm \text { SD }\end{array}$ & $.49 \pm .37$ & $.62 \pm .40$ & $1.83 \pm .94$ & $2.01 \pm 1.05$ & $1.91 \pm .86$ & $2.12 \pm .91$ \\
\hline $\begin{array}{c}\text { Posterior } \\
\mathrm{X} \pm \text { SD }\end{array}$ & $.45 \pm .34$ & $.55 \pm .41$ & $1.82 \pm .47$ & $2.00 \pm .79$ & $2.42 \pm .61$ & $2.50 \pm .48$ \\
\hline $\begin{array}{c}\text { MannWhitney Test } \\
\text { (p value) }\end{array}$ & .32 & .34 & .50 & .42 & $.022 *$ & $.041 *$ \\
\hline \multicolumn{7}{|c|}{ implant mobility } \\
\hline $\begin{array}{l}\text { Anterior } \\
\mathbf{X} \pm \text { SD }\end{array}$ & $65.45 \pm 1.77$ & $66.70 \pm 1.61$ & $65.01 \pm 1.68$ & $66.40 \pm 1.62$ & $66.40 \pm 1.59$ & $67.80 \pm 1.01$ \\
\hline $\begin{array}{c}\text { Posterior } \\
\mathrm{X} \pm \text { SD }\end{array}$ & $66.25 \pm 1.88$ & $67.01 \pm 1.64$ & $67.25 \pm 1.78$ & $67.01 \pm 1.68$ & $67.15 \pm 1.96$ & $68.10 \pm 1.87$ \\
\hline $\begin{array}{c}\text { Mann Whitney Test } \\
\text { (p value) }\end{array}$ & .63 & .46 & .53 & .66 & .55 & .42 \\
\hline \multicolumn{7}{|c|}{ bone resorption } \\
\hline $\begin{array}{l}\text { Anterior } \\
\mathbf{X} \pm \text { SD }\end{array}$ & - & - & $.52 \pm .85$ & $.69 \pm .78$ & $.84 \pm .74$ & $.97 \pm 1.18$ \\
\hline $\begin{array}{c}\text { Posterior } \\
\mathrm{X} \pm \mathrm{SD}\end{array}$ & - & - & $.68 \pm .43$ & $.76 \pm .24$ & $.98 \pm .75$ & $1.1 \pm .65$ \\
\hline $\begin{array}{c}\text { MannWhitney Test } \\
\text { (p value) }\end{array}$ & & & .88 & .45 & .14 & .083 \\
\hline
\end{tabular}

Med= median, $\operatorname{mini}=$ minimum $;$ maxi $=$ maximum; $\mathrm{X}=$ mean; $\mathrm{SD}=$ Standard deviation; $*$ = significant at .05 level. 


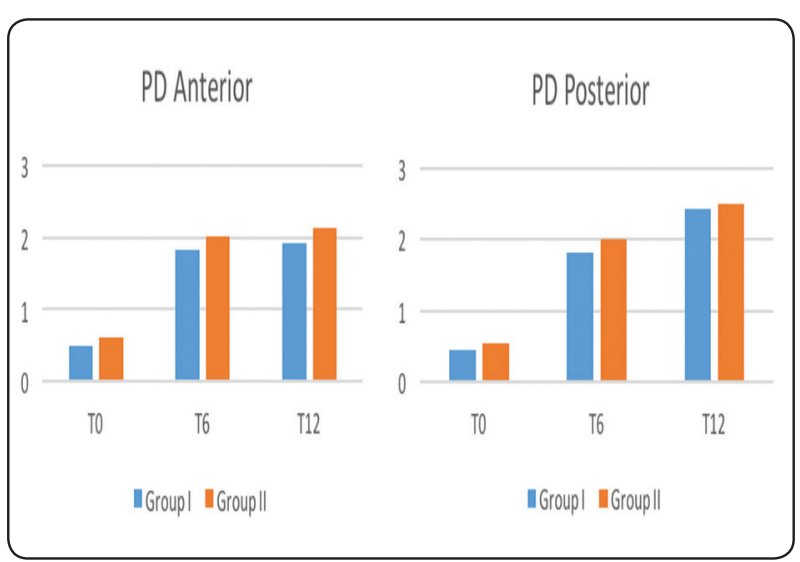

Fig. (9): Pocket depth for anterior and posterior implants at different time intervals for both groups

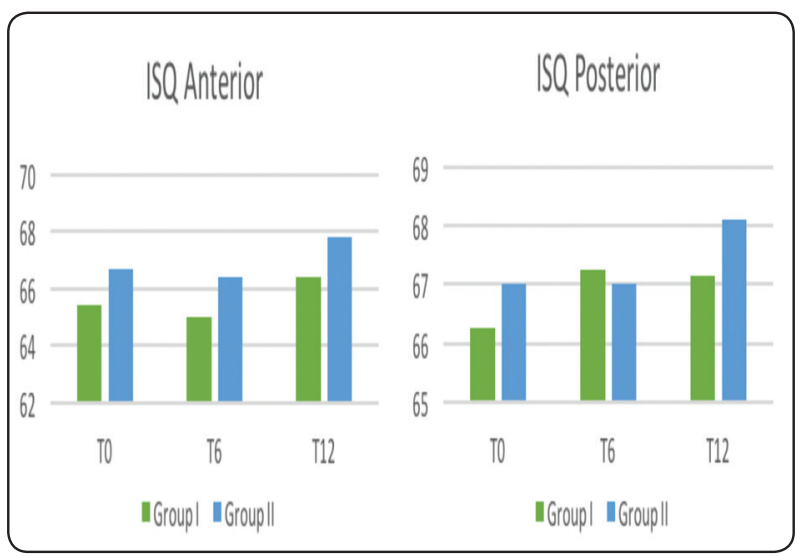

Fig. (10): Implant mobility for anterior and posterior implants at different time intervals for both groups

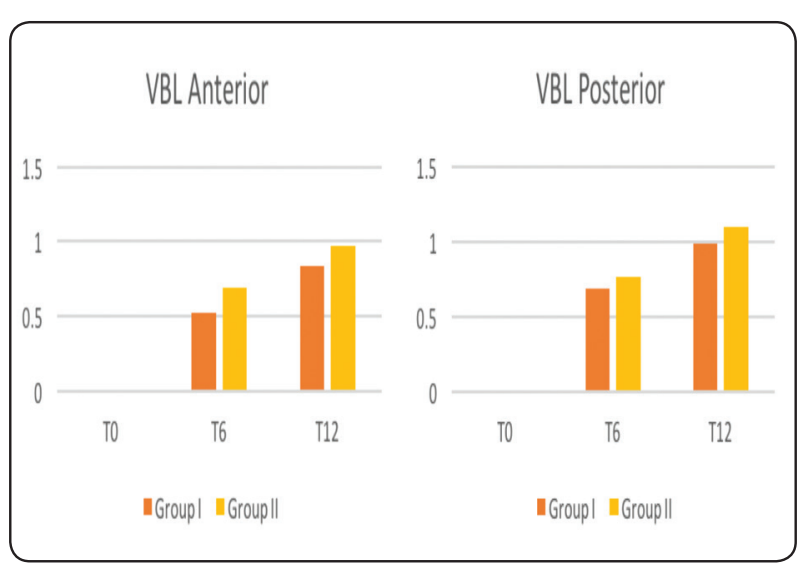

Fig. (11): Bone loss for anterior and posterior implants at different time intervals for both groups

\section{DISCUSSION}

Cone-beam computed tomography (CBCT) provides three-dimensional images and consequently additional information in comparison with the twodimensional periapical radiographs ${ }^{22}$. Cross-sectional images obtained using CBCT allow visualization of the bucco-lingual bone surrounding dental implants ${ }^{23}$. Therefore, CBCT was used for evaluation of marginal bone loss in buccal and lingual sites besides mesial and distal which is not applicable in case of periapical radiographs.

The plaque and gingival indices increased with time for both groups. The same finding was also noted by Ayna et al. ${ }^{24}$ for metal ceramic fixed prosthesis. The increased plaque accumulation may be attributed to the decreased manual dexterity of old participants causing in reduced cleaning. Moreover, the increased atrophy in both groups is accompanied by an elevated floor of the mouth and consequently with changes in location of the salivary glands enhancing the formation of calculus and plaque $^{25}$. The increase plaque accumulation causes increased gingival inflammation and consequently gingival scores increased. Similarly, Ayna et al. ${ }^{24}$ attributed the increased gingival indices to the higher plaque accumulation. In contrast to these findings, some authors had reported that there is no time effect on plaque and bleeding indexes between groups and plaque and bleeding indices improved from 6 to 12 months regarding using mandibular fixed prosthesis with All On Four concept ${ }^{16,26}$. The increased plaque and gingival scores for group II compared to group I may be due to decreased interimplant distance between anterior and posterior implants which complicate oral hygiene procedures. In line with observation, Abi Nader et al ${ }^{27}$ reported that plaque accumulation was influenced by the distance between the inserted implants. Also, these results are in line with other investigations, in which the authors reported that the wider inter-implant distance, cause reduced plaque accumulation on the surfaces of these implants ${ }^{16,26}$. 
Another explanation could be attributed to the distal cantilever in group II which provide sheltered area for plaque to accumulate and make cleaning more difficult. For group II, posterior implants showed significant higher plaque index, and gingival index than anterior implants. A similar finding was noted by Krennmair et al ${ }^{25}$ who compared axial and tilted implants supporting All-On-Four mandibular fixed prosthesis. They attributed this finding to the impaired cleaning process of posterior implants caused by prosthesis design with excessively close gingival attachment due to the inaccessibility of posterior implant compared to anterior implants.

The pocket depth increased significantly with passage of time for both groups. In agreement with this observation, several authors reported an increase in pocket depth around implants supporting "All On Four" prosthesis ${ }^{24,25}$. The increased pocket depth with time may be attributed to the increased plaque accumulation, gingival inflammation, marginal bone resorption and mucosal enlargement around the implants ${ }^{28}$. For both groups, pocket depth of posterior implants was significantly higher than anterior implants after 12 months. This may be due to increased plaque accumulation and gingival inflammation and enlargement around posterior implant.

Another explanation may be attributed to the surgical technique used for placement of posterior (inclined) implants which necessitate subcrestal merging of the inclined implants with preparation of occlusal flare in the crestal bone to accommodate the multiunit abutments. This may increase bone loss and creates deeper pockets around posterior implants compared to anterior ones. This could explain also why pocket depth did not differ between groups as the same surgical technique was used in both groups. In contrast, Krennmair, et al. ${ }^{25}$ found that pocket depth did not differ between anterior and posterior implants.

Resonance frequency analysis was used to evaluate implant mobility as it is noninvasive method that allow verification of implant mobility during healing and in subsequent evaluations ${ }^{29}$. Implant mobility values obtained in all observation times was above 60. No difference in implant mobility was noted between groups or anterior and posterior implants. This may be due to all implants are inserted in the interforaminal area of the mandible which characterized by increased bone quality and density. The lack of difference in implant mobility between anterior (vertical) and posterior (tilted) implants was in line with results of other studies ${ }^{29-31}$.

The results of the present study demonstrated a significant increase in bone resorption with passage of time. This may be due to the natural biological process of bone remodeling which occurs after implant placement and immediate bone response to healing and reorganization combined with function stresses $^{32}$. The amount marginal bone loss after one year not exceeds $1.1 \mathrm{~mm}$. This rate of bone loss remains within the normal rate which is $1.2 \mathrm{~mm}$ in the first year ${ }^{33-37}$.

The cantilever length of implant supported prosthesis is a critical factor in the transfer of the occlusal load to the fixtures and the supporting bone $^{38}$. Cantilever lengths differ with biologic and mechanical factors, and bone quality is the most critical criteria in detecting the cantilever length. The ideal cantilever length is that which allows uniform distribution of the functional forces to the bone without overloading the implant/bone interface ${ }^{39}$. Zyl et al ${ }^{12}$ reported that cantilever extension beyond $15 \mathrm{~mm}$ may cause increased stress in the lingual and buccal sides of the implants, which may affect the osseointegration of the implants. Greater stresses may cause the interfacial strain to reach the pathologic overload zone and may cause microfracture of the bone, fibrous tissue formation, and/or bone resorption. ${ }^{14}$

The most interesting finding of this study, that there was no significant difference in marginal bone loss between prosthesis with and without cantilever extensions. This could be attributed to the 
shortened cantilever length utilized in the present study. Cantilever length / Anterior-posterior spread ratio was suggested to be of 1.5 as guides for the maximum allowable cantilever extension which is dependent on the number of implants and distance between the most anterior and posterior implants ${ }^{40}$. In this study the cantilever length did not exceed this ratio as only one molar was added as a cantilevered pontic (with maximum mesiodistal width of $12 \mathrm{~mm}$ ). Another explanation may be attributed to the opposing dentition which is conventional dentures in both groups thus transmitting reduced forces to the implant compared to natural dentition or fixed prosthesis during function and parafunction ${ }^{41}$. Moreover, the favorable bone density observed in the mandibular anterior ridge permits a cantilever extensions ranged from 15 to $20 \mathrm{~mm}^{42}$. Similarly, several clinical reports indicated that cantilevers of conventional fixed partial dentures on parallel implants did not lead to increased bone resorption around supporting implants and that the higher stresses on the implants with cantilevers was still be within the physiologic adaptive capacity of the surrounding bone $\mathrm{e}^{43-45}$

In line with this observation, Malhotra and Padmanabhan ${ }^{14}$ did not found a significant difference in stress and strain between $4 \mathrm{~mm}$ and $12 \mathrm{~mm}$ cantilevers for both $30^{\circ}$ and $40^{\circ}$ posteriorly inclined implants using finite element analysis. In contrast, Horita, Sugiura et al. ${ }^{13}$ reported that mandibular fixed full-arch prostheses without cantilevers may result in a favorable reduction of the peri-implant bone strain during the healing period, compared with cantilevers. They added that the high compressive stress in the $15-\mathrm{mm}$ cantilever models causing a $33 \%$ increase in stresses compared with the 5-mm cantilevers. However, for strain to be pathologic it should reach certain level. In this study the stain resulted from short cantilever appears to be located within the normal physiologic zone. Therefore an increased bone modelling occurs, which causes a woven bone formation rather than bone resorption. ${ }^{14}$

For both groups, no significant difference of marginal bone loss between anterior and posterior implants was noted at all observation times. This may be due to distal inclination of posterior implants that permits for reduction or elimination of the cantilever length, resulting in reduced stresses in the bone around the implants as stated by ${ }^{46,47}$. Moreover ,the use of tilted implants increased the anteriorposterior spread, splinting the implants with a rigid superstructure may contribute to a favorable pattern of bone resorption regardless of the axial or tilted implant placement ${ }^{25}$. This was in agreement with Khatami et al., who stated that if tilted implants are part of a multiple implant-supported prosthesis, the spread of the implants and rigidity of the prosthesis will reduce or change the nature of bending forces ${ }^{48}$. Similar to these findings, a clinical study by Lopes et al., found no difference in bone resorption between vertically and posteriorly tilted fixtures after 5 -year ${ }^{49}$

\section{CONCLUSION}

Within the limitation of this study, fixed prosthesis with short cantilever can be used successfully to rehabilitate patients with atrophied mandibular ridges and anteriorly placed mental foramen with "All on four" concept as it was associated with favourable clinical and radiographic outcomes similar to prosthesis without cantilevers.

\section{REFERENCES}

1. Walton JN, MacEntee MI. A retrospective study on the maintenance and repair of implant-supported prostheses. Int J Prosthodont. 1993;6:451-5.

2. Weinstein R, Agliardi E, Fabbro MD, Romeo D, Francetti L. Immediate rehabilitation of the extremely atrophic mandible with fixed full-prosthesis supported by four implants. Clin Implant Dent Relat Res. 2012;14:434-41.

3. Del Fabbro M, Testori T, Francetti L, Weinstein R. Systematic review of survival rates for implants placed in the grafted maxillary sinus. Int J Periodontics Restorative Dent. 2004;24:565-77.

4. Vetromilla BM, Moura LB, Sonego CL, Torriani MA, Chagas OL. Complications associated with inferior alveolar nerve repositioning for dental implant placement: a systematic review. Int J Oral Maxillofac Surg. 2014; 43:1360-6. 
5. Malo P, Rangert B, Nobre M. "All-on-Four" immediatefunction concept with Branemark System implants for completely edentulous mandibles: a retrospective clinical study. Clin Implant Dent Relat Res. 2003;5 Suppl 1:2-9.

6. Malo P, Rangert B, Nobre M. All-on-4 immediate-function concept with Branemark System implants for completely edentulous maxillae: a 1-year retrospective clinical study. Clin Implant Dent Relat Res. 2005;7 Suppl 1:S88-94.

7. Pozzi A, Sannino G, Barlattani A. Minimally invasive treatment of the atrophic posterior maxilla: a proof-of-concept prospective study with a follow-up of between 36 and 54 months. J Prosthet Dent. 2012;108:286-97.

8. Francetti L, Agliardi E, Testori T, Romeo D, Taschieri S, Del Fabbro M. Immediate rehabilitation of the mandible with fixed full prosthesis supported by axial and tilted implants: interim results of a single cohort prospective study. Clin Implant Dent Relat Res. 2008;10:255-63.

9. Krekmanov L. Placement of posterior mandibular and maxillary implants in patients with severe bone deficiency: a clinical report of procedure. Int J Oral Maxillofac Implants. 2000;15:722-30.

10. Jensen OT, Adams MW, Cottam JR, Parel SM, Phillips WR. The all on 4 shelf: mandible. J Oral Maxillofac Surg. 2011;69:175-81.

11. Sannino G, Bollero P, Barlattani A, Gherlone E. A Retrospective 2-Year Clinical Study of Immediate Prosthetic Rehabilitation of Edentulous Jaws with Four Implants and Prefabricated Bars. J Prosthodont. 2017;26:387-94.

12. van Zyl PP, Grundling NL, Jooste $\mathrm{CH}$, Terblanche E. Three-dimensional finite element model of a human mandible incorporating six osseointegrated implants for stress analysis of mandibular cantilever prostheses. Int J Oral Maxillofac Implants. 1995;10:51-7.

13. Horita S, Sugiura T, Yamamoto K, Murakami K, Imai Y, Kirita T. Biomechanical analysis of immediately loaded implants according to the "All-on-Four" concept. J Prosthodont Res. 2017;61:123-32.

14. Malhotra AO, Padmanabhan TV. Load transfer in tilted implants with varying cantilever lengths in an all-on-four situation. Aust Dent J. 2012;57(4):440-5.

15. Cawood JI, Howell RA. A classification of the edentulous jaws. Int J Oral Maxillofac Surg. 1988;17:232-6.

16. Agliardi E, Panigatti S, Clerico M, Villa C, Malo P. Immediate rehabilitation of the edentulous jaws with full fixed prostheses supported by four implants: interim results of a single cohort prospective study. Clin Oral Implants Res. 2010;21:459-65.
17. Malo P, de Araujo Nobre M, Lopes A, Francischone C, Rigolizzo M. "All-on-4" immediate-function concept for completely edentulous maxillae: a clinical report on the medium ( 3 years) and long-term ( 5 years) outcomes. Clin Implant Dent Relat Res. 2012;14 Suppl 1:e139-50.

18. Mombelli A, van Oosten MA, Schurch E, Jr., Land NP. The microbiota associated with successful or failing osseointegrated titanium implants. Oral Microbiol Immunol. 1987; 2:145-51

19. Elsyad MA, Elsaih EA, Khairallah AS. Marginal bone resorption around immediate and delayed loaded implants supporting a locator-retained mandibular overdenture. A 1-year randomised controlled trial. J Oral Rehabil. 2014;41:608-18.

20. Elsyad MA, Mahanna FF, Elshahat MA, Elshoukouki AH. Locators versus magnetic attachment effect on periimplant tissue health of immediate loaded two implants retaining a mandibular overdenture: a 1-year randomised trial. J Oral Rehabil. 2016;43:297-305.

21. Elsyad MA, Khirallah AS. Circumferential bone loss around splinted and nonsplinted immediately loaded implants retaining mandibular overdentures: A randomized controlled clinical trial using cone beam computed tomography. J Prosthet Dent. 2016;116 741-8

22. Raes F, Renckens L, Aps J, Cosyn J, De Bruyn H. Reliability of circumferential bone level assessment around single implants in healed ridges and extraction sockets using cone beam CT. Clin Implant Dent Relat Res. 2013;15:661-72.

23. Naitoh M, Hayashi H, Tsukamoto N, Ariji E. Labial bone assessment surrounding dental implant using cone-beam computed tomography: an in vitro study. Clin Oral Implants Res. 2012;23:970-4.

24. Ayna M, Gulses A, Acil Y. A comparative study on 7-year results of "All-on-Four" immediate-function concept for completely edentulous mandibles: metal-ceramic vs. barretained superstructures. Odontology. 2018;106:73-82.

25. Krennmair S, Weinländer M, Malek M, Forstner T, Krennmair G, Stimmelmayr M. Mandibular Full-Arch Fixed Prostheses Supported on 4 Implants with Either Axial Or Tilted Distal Implants: A 3-Year Prospective Study. Clin Implant Dent Relat Res. 2016;18:1119-33.

26. Barrio LD, Cosyn J, Paula WN, Bruyn H. A prospective study on implants installed with flapless-guided surgery using the all-on-four concept in the mandible. Clin Oral Implants Res. 2013;24(4):428-33.

27. Abi Nader S, Eimar H, Momani M, Shang K, Daniel NG, Tamimi F. Plaque Accumulation Beneath Maxillary Allon-4 Implant-Supported Prostheses. Clin Implant Dent Relat Res. 2015;17:932-7. 
28. Elsyad MA, Denewar BA, Elsaih EA. Clinical and Radiographic Evaluation of Bar, Telescopic, and Locator Attachments for Implant-Stabilized Overdentures in Patients with Mandibular Atrophied Ridges: A Randomized Controlled Clinical Trial. Int J Oral Maxillofac Implants 2018;33:1103-11.

29. Ayub KV, Ayub EA, Lins do Valle A, Bonfante G, Pegoraro T, Fernando L. Seven-Year Follow-up of Full-Arch Prostheses Supported by Four Implants: A Prospective Study. Int J Oral Maxillofac Implants 2017;32:1351-8.

30. Balshi SF, Allen FD, Wolfinger GJ, Balshi TJ. A resonance frequency analysis assessment of maxillary and mandibular immediately loaded implants. Int J Oral Maxillofac Implants 2005;20:584-94.

31. Balshi TJ, Wolfinger GJ, Slauch RW, Balshi SF. A retrospective analysis of 800 Branemark System implants following the All-on-Four protocol. J prosthodontics. 2014;23:83-8.

32. Hohlweg-Majert B, Metzger MC, Kummer T, Schulze D. Morphometric analysis - Cone beam computed tomography to predict bone quality and quantity. J Craniomaxillofac Surg. 2011;39:330-4.

33. Albrektsson T, Zarb G, Worthington P, Eriksson AR. The long-term efficacy of currently used dental implants: a review and proposed criteria of success. Int J Oral Maxillofac Implants. 1986;1:11-25.

34. Albrektsson T, Zarb GA. Current interpretations of the osseointegrated response: clinical significance. Int J Prosthodont. 1993;6:95-105.

35. Zarb GA, Albrektsson T. Consensus report: towards optimized treatment outcomes for dental implants. J Prosthet Dent. 1998;80:641.

36. van Steenberghe D, Quirynen M, Naert I, Maffei G, Jacobs R. Marginal bone loss around implants retaining hinging mandibular overdentures, at 4-, 8- and 12-years follow-up. J Clin Periodontol. 2001;28:628-33.

37. Chung DM, Oh TJ, Lee J, Misch CE, Wang HL. Factors affecting late implant bone loss: a retrospective analysis. Int J Oral Maxillofac Implants. 2007;22:117-26.

38. Skalak R. Biomechanical considerations in osseointegrated prostheses. J Prosthet Dent. 1983;49:843-8.
39. Sertgoz A, Guvener S. Finite element analysis of the effect of cantilever and implant length on stress distribution in an implant-supported fixed prosthesis. J Prosthet Dent. 1996;76:165-9.

40. McAlarney ME. Determination of cantilever length-anterior-posterior spread ratio assuming failure criteria to be the compromise of the prosthesis retaining screw-prosthesis joint. Int J Oral Maxillofac Implants. 1996;11(3):331-9.

41. Tashkandi EA, Lang BR, Edge MJ. Analysis of strain at selected bone sites of a cantilevered implant-supported prosthesis. J Prosthet Dent. 1996;76:158-64.

42. Rangert BO, Jemt T. Forces and Moments on Brånemark Implants. Int J Oral Maxillofac Implants. 1989;4(3):241-7

43. Romeo E, Lops D, Margutti E, Ghisolfi M, Chiapasco M, Vogel G. Implant-supported fixed cantilever prostheses in partially edentulous arches. A seven-year prospective study. Clin Oral Implants Res. 2003;14:303-11.

44. Halg GA, Schmid J, Hammerle CH. Bone level changes at implants supporting crowns or fixed partial dentures with or without cantilevers. Clin Oral Implants Res. 2008;19:983-90.

45. Wennstrom J, Zurdo J, Karlsson S, Ekestubbe A, Grondahl $\mathrm{K}$, Lindhe J. Bone level change at implant-supported fixed partial dentures with and without cantilever extension after 5 years in function. J Clin Periodontol. 2004;31:1077-83.

46. Bellini CM, Romeo D, Galbusera F. A finite element analysis of tilted versus nontilted implant configurations in the edentulous maxilla. Int J Prosthodont. 2009;22(2):155-7

47. Zampelis A, Rangert B, Heijl L. Tilting of splinted implants for improved prosthodontic support: A two-dimensional finite element analysis. J Prosthe Dent. 2007;97:S35-S43.

48. Khatami AH, Smith CR. "All-on-four" immediate function concept and clinical report of treatment of an edentulous mandible with a fixed complete denture and milled titanium framework. J Prosthodontics. 2008;17:47-51.

49. Lopes A, Malo P, de Araujo Nobre M, Sanchez-Fernandez E, Gravito I. The NobelGuide(R) All-on-4(R) Treatment Concept for Rehabilitation of Edentulous Jaws: A Retrospective Report on the 7-Years Clinical and 5-Years Radiographic Outcomes. Clin Implant Dent Relat Res. 2017;19:233-44. 